\title{
Language Ideologies and Language Practices in Health Services: Patients' Experiences in Post-Colonial Zimbabwe
}

\author{
Busani Maseko \\ ORCID iD: https://orcid.org/0000-0002-7968
}

\section{Prisca Matunge}

\section{Abstract}

Language is the most important means through which patients access health care services and health information. Language policy, and particularly the use of languages better understood by patients, is therefore critical in any clinical encounter. Within language policy studies, decolonial discourses and scholarship have tended to begin and end with the politics and problematisation of the colonially inherited English language as a 'recurring decimal' in education, the media and other public spaces. In this article, we discuss language experiences of patients who had previously sought medical assistance in selected hospitals in Zimbabwe to expose how doctors' and nurses' language practices are a reproduction of structures and orders of power. These power inflected practices foreground Shona language as the natural, uncontested alternative to English, to the detriment of other African indigenous languages and their speakers. Through a triangulation of Spolsky's notion of language policy and Bourdieu's concept of symbolic domination, we attempt to show how doctors' and nurses' preference for the use of Shona in clinical encounters with non-Shona patients validates the pervasive Shona hegemonic ideology and domination. This hegemony which is palpable in almost all spheres of life in postcolonial Zimbabwe ultimately projects Shona as the "new recurring decimal'. The endeavor to decolonise the Zimbabwean linguistic ecology has degenerated into a new linguistic order, one bordering on unofficial proscription and exclusion of other languages. We recommend a rethink of language policy in health, to embrace professional interpreter services and 
deployment of language concordant health practitioners to foster inclusive health services provision.

Keywords: Decolonial discourses language ideologies Language policy, patients' language experiences, symbolic domination.

\section{Introduction}

Within language policy studies in Africa, decolonial discourses have often been couched on problematising the continued use of English as a relic of colonialism (Christie \& McKinney 2017). Many explanations for the enduring status of English as an official language in Anglophone countries have been proffered (see for example Bamgbose 1991; Kadenge \& Nkomo 2011; Nkomo and Maseko, 2017). English is undeniably the most powerful of global languages, owing to a combination of its demographic superiority, further buttressed by the political and economic power wielded by the English speaking world and by English in general (Bamgbose 2003). English is therefore a language of power, and the proficiency in it accords its speakers power and prestige to reveal its hegemony, and to benefit from its communicative and instrumental utility in the context of a globalised and globalising world (Bamgbose 2003). The pervasiveness and ubiquity of English particularly in education, the media, the judiciary services and other formal domains has thus been problematised aptly by Bamgbose along the metaphor of a 'recurring decimal' (cf. Bamgbose 2003). This mathematical expression is deployed by Bamgbose to explain the omnipresent problem of English in the language policy discourse in Africa. Decolonial scholarship has also lamented this inheritance situation (Bamgbose 1991; 2003) as a stumbling block in the quest for complete decolonisation, which is 'aimed at liberating colonised peoples and deimperialising imperial power' (Ndlovu-Gatsheni 2015:22). Given the importance of language in forming and sustaining an identity, increasing scholarship on decoloniality has emphasised the need to recalibrate the African linguistic ecology, to an extent that it reflects the new envisaged postcolonial reality, one denominated by African solutions to African problems and realities. Central to the language problems of postcolonial Africa is the issue of communication across multilingual and multicultural spaces (Bamgbose 1991). The continued use of English thus presents a communication problem, particularly for an African population who speaks it as a second language (L2). Because 'English is largely acquired 
through formal education, its detrimental effects can be seen in social stratification, exclusion, and problems associated with education and literacy, status of languages other than English and language rights' (Bamgbose 2003:419).

Within language policy scholarship, the grand narrative has therefore been framed around the need to nurse this colonial hangover by promoting the use of indigenous African languages in domains hitherto thought of as preserves for English. While the case for the use of indigenous African languages has been made in the domains of education, the media, the judiciary, and other spaces, few studies have been done in the domain of language policy, to make sense of language policy and practices in health services provision, and particularly how language policy and practices in health are enmeshed intimately with structures and orders of power. In multilingual settings, communication is an essential aspect of health service delivery and language is the central and most important vehicle by which patients interact with the healthcare service providers. Yeo (2004:59f) adds that:

Language is also the means by which a health care service provider accesses a patient's beliefs about health and illness, and thus creates an opportunity to address and reconcile different belief systems. In essence, communication between nurses and patients is the heart of nursing care.

In this article we locate the decolonisation discourse within the ambits of language policy and language practices in health service provision in Zimbabwe. In particular, we discuss how doctors' and nurses' use of Shona language in clinical encounters with non-Shona speakers reproduces orders and structures of power in post-colonial Zimbabwe. By examining patients' reported language experiences in selected hospitals in the predominantly minoritised language speaking district of Hwange in Matabeleland North, we discuss how the attempt to decolonise the Zimbabwean linguistic space has had the undesirable outcome of projecting Shona as the natural, shoe-in, and Godgiven alternative to English in health service provision, as it has been in various other domains. In this article, we triangulated Bernard Spolsky's (2004; 2009) views on language policy and Jean Pierre Bourdieu's (1991) notion of symbolic dominance to make sense of doctors' and nurses' practice of using Shona in clinical encounters involving non-Shona patients, despite the threat 
of a diminished quality of the clinical encounter which may consequently curtail and impact overall health outcomes (Yeo 2004). We argue that the use of Shona as the uncontested alternative to English is certainly not innocent (Ncube and Siziba 2017) but is imbued and entangled with 'relations of symbolic power in which the power relations between speakers or respective groups are realised' (Loos 2000:2).It is therefore a reflection of the hierachisation of the cultural, linguistic and political space which situates Shona linguistic and cultural heritage as synonyms for Zimbabwean-ness, to the detriment of other languages and cultures (Ncube \& Siziba 2017). To problematise this situation, we appropriate the concept of 'Shonalisation' (Msindo 2005; Ndhlovu 2009; Ncube \& Siziba 2017) as an explanation of how language practices in health service provision represent a microcosm of Shona dominated statewide language practices. We argue that Shona derives its dominance and hegemony from the demographic, economic, and political superiority of its speakers, in the same vein that English did during the colonial era and still does in the post-colonial epoch. The endeavour to decolonise the Zimbabwean language ecology has degenerated into a new linguistic order, one that presents Shona as the new 'recurring decimal' (Bamgbose 2003). The preponderance of Shona (Ndhlovu 2009) therefore presents a dilemma for the decolonial project in Zimbabwe as it reproduces the 'colonial matrix of power' (Christie \& McKinney 2017), seemingly supported by the post-colonial government through various popularisation projects (Ndhlovu 2009).

In the provision of health services, the compulsion of Shona, as read from doctors' and nurses' language practices results in exclusion of speakers of other languages because of the language barrier, thereby perpetuating a vicious cycle. Spolsky illustrates vividly the potentially fatal outcomes related to the language barrier in health in the following example:

A fifty-six-year-old Turkish woman was refused a heart transplant by clinics in Hanover on the grounds that her lack of German (common among Gastarbeiter) made the recovery process dangerous. The clinic defended the decision: the patient might not understand the doctors' orders, might take the wrong medicine and might not be able to get help if there were complications (Spolsky 2004:1)

The above quote demonstrates the supremacy of language policy for inclusive healthcare to be achieved. Inclusive of this introduction, this paper is divided 
into seven main sections. In the next section, we discuss the context of the study, followed by an exposition of the theoretical lens that undergirds the study. We then go on to discuss the literature review, to show the lacuna which the study seeks to address, which is succeeded by a discussion of the methodlogical approach deployed in the study. The paper then delves into the presentation and discussion of findings. The last section is the conclusion of the study.

\section{Research Context}

This paper presents selected findings of a larger study that focused on language policy in health care. The study was conducted in Hwange, a highly multilingual district in Matabeleland North Province of Zimbabwe in 2019. The constitution of Zimbabwe (Government of Zimbabwe 2013) declared multilingualism as the norm than an exception through its official recognition of 16 languages. Among those, a good number of them are spoken predominantly in Matabeleland North Province. In fact, Hwange district is considered to be the cradle of the formerly minority languages such as Nambya, Chewa, Tonga and Dombe, among others (Ndhlovu 2009). Ndebele and Shona languages are also spoken in the district. The proximity of Hwange to the predominantly Ndebele speaking Lupane and Tsholotsho districts probably accounts for the presence of Ndebele. As for Shona language, its presence in Hwange can be explained within the context of a 'migrant' labour force deployed in government departments such as health, education, home affairs and in parastatals such as Hwange Colliery Company (HCC) and the Zimbabwe Power Company (ZPC). Some Ndebele speakers are also located in the district for the same reason. Although Matabeleland North in general is considered to be an enclave of the former minority languages, the language politics of Zimbabwe have resulted in their diminished usage in public institutions, with Shona and Ndebele assuming the status of de-facto 'official languages' in the province in varying extents. Ndhlovu (2008a; 2009) has given a compelling account of this consequence. He argues that the dominance of Shona and Ndebele as the major endoglossic languages can be traced to the works of pre-independence linguist, professor Clement M. Doke who was tasked by the colonial government to research and make recommendations for 'resolving language problems in Mashonaland' (Ndhlovu 2009:29). While it is not compelling for the present paper to rehash the manner in which Doke did his work, what should be of interest are the recommendations he subsequently 
made for the whole country; this after having 'travelled from Salisbury to all parts of the country, visiting every native commissioner and every mission station' (Chimhundu 1992:105), in the process overstepping his mandate. He eventually submitted a report wherein he made recommendations for Matabeleland, stating that for Matabeleland, only Ndebele be used in education and Shona be the only language used in Mashonaland (Msindo 2005; Ndhlovu 2008a). The net effect of these recommendations was to present the country as a 'bimodal ethnicity' (Ndlovu-Gatsheni 2008). Resultantly, the recommendations occasioned the various forms of language based marginalisation, particularly for the excluded speakers of these minoritised languages (cf. Ndhlovu 2009). Although the real picture is far from being this simplistic, it is generally agreed by scholars of language policy in Zimbabwe that postindependence state formation has tended to follow a similar pattern. Shona and Ndebele languages, and their speakers have been ameliorated at the expense of the formerly minority languages, owing to their domination of the national culture. Although the diglossic relationship between Ndebele and Shona languages themselves is another contentious subject (Nkomo \& Maseko 2017), the dominance of the Shona elite in Zimbabwean politics, government, and other public and official spaces has tended to cast Shona language as the 'default marker of Zimbabwean-ness' (Ncube \& Siziba 2017:829). Predictably, language practices in public institutions such as the health services delivery have had 'to contend with the structuring of power in Zimbabwe' (Ncube \& Siziba 2017:829).

For Matabeleland, much of the language problems and language barriers in health have been attributed to a skewed recruitment and deployment of health personnel. In Matabeleland, this has generated public outcry, with some residents berating openly government's nurse recruitment, training, and deployment policy, which seem to favour applicants from Mashonaland. For example, one resident was quoted in the Bulawayo based Chronicle newspaper chiding the authorities on the issue, particularly how the centralisation of recruitment in Harare results in diminished prospects for Matabeleland based applicants making the shortlist:

What they have simply done is to declare that as a people from this region we do not deserve access to health care. From the list of 24, only four students are from this region and it is clear that they are not worried about our right to health (Chronicle October 9, 2019). 
The centralisation of nurse recruitment and 'the compulsion of Harare' (Ncube \& Siziba 2017) in general, is treated with suspicion by the people of Matabeleland, thereby fostering and engendering narratives that have so far been couched on the ideology of 'deliberate marginalisation of Matabeleland prospective students' (Chronicle October 9, 2019).

\section{Language Ideologies, Language Practices, and Symbolic Domination}

This study is undergirded, to a considerable extent, by Spolsky's (2004; 2009) views regarding language policy, as well as Jean Pierre Bourdieu's (1991) concept of symbolic domination to unpack how language practices in doctor/nurse-patient clinical encounters and linguistic exchanges are infused with the ideologies of dominant languages as 'linguistic capital for symbolic power' (Loos 2000:2). Spolsky's theory of language policy is couched on the thinking that:

Language policy is all about choices. If you are bilingual or plurilingual, you have to choose which language to use. Even if you speak only one language, you have choices of dialects and styles. To understand the nature of this process, one needs an ecological model that will correlate social structures and situations with linguistic repertoires (Spolsky 2009: 4).

Language policy is ever present, even if not explicitly stated as an official position. In any case, absence of a policy could be an implicit policy to maintain the status quo (Bamgbose 1991). According to Pennycook (2013: 2), 'language policy operates at multiple levels and through multiple agents, from those working to maintain a language in the face of state support for other languages, to commercial interests promoting particular versions of a language.' For this study, we are certainly in agreement with, and accept the view that 'doctors and hospitals make language policy when they decide how to deal with language diversity.' (Spolsky 2004:1). All spheres of society are therefore subject to language policy, which, according to Spolsky, is mediated by three interrelated components; i.e. language practices, language ideologies, and management. Language practices are the regular and predictable behaviours relating to language choice in a speech community (Ren \& $\mathrm{Hu}$ 
2013) or 'the habitual pattern of selecting among the varieties that make up its linguistic repertoire' (Spolsky 2004:5). Practices are the overt and observable linguistic behaviours of language users in a community, institution, or state. Practices are what people actually do with their languages or language varieties (Spolsky 2004). Some practices and choices are made consciously, reflecting the speakers' ideologies about their language and that of others.

Language ideologies are the beliefs that language users have about their language(s). They are 'what people think should be done' (Spolsky 2004:14). Ideologies therefore lead speakers to make certain choices relating to language practices and they also inform consensual and 'common-sense' practices, assigning values and prestige to certain languages or language varieties (Spolsky 2009). Put differently, language ideologies are '...selfevident ideas and objectives a group holds concerning roles of language in the social experiences of members as they contribute to the expression of the group' (Heath cited in Woolard \& Schieffelin 1994: 57). Subjective reactions to the value and prestige ascribed to a language are related to variables such as the speakers' demographic dynamics, the importance of the language to its users, and the socio-economic benefits a speaker can expect by using it (Spolsky 2009). However, the relationship between language ideologies and language practices in any community is dialectical in the sense that ideologies may impact and be impacted by practices. Together they potentially 'designate a speech community's consensus on what value to apply to each of the language variables or named language varieties that make up its repertoire' (Spolsky 2004:14).

Because language ideologies and practices have the potential to present certain languages and their use as 'the natural order of things' (Ncube \& Siziba 2017:829), users of such languages tend to acquire 'symbolic power' in so far as their languages become endowed with 'symbolic capital' (Bourdieu 1991). They are able to compel speakers of other languages to capitulate to the use of the dominant language and ideology, with such practices being presented as 'God-given' and unavoidable, consequently relegating to the margins, other alternative ways of being (Ncube \& Siziba 2017). Drawing on the notions of language ideologies, language practices, and symbolic domination, we attempt to explain how language choices by doctors and nurses in their clinical encounters with patients are in fact a reproduction of 'social hierarchies or hierarchies of power, and that there is nothing neutral about one language's dominance in any given context' (Ncube \& Siziba 2017:829 
quoting Bucholtz and Hall). Using the market metaphor, Bourdieu has demonstrated how some linguistic products in the market are endowed with more symbolic capital than others, allowing their users to exert symbolic domination on others (Loos 2000:8).

\section{Literature Review}

Although there is vast literature on language policy and language practices in Zimbabwe, much of it focuses on education (for example Ndlovu 2013) while other studies have attempted to understand language policies, ideologies, and practices in the media (e.g. Mpofu 2013). Further, some studies, although few, have focused on language policy in the justice delivery services. Recently, there has been a considerable interest in the mechanics of language policy and its articulation in the more informal micro domains of the community such as the family, an approach aptly termed 'family language policy' (e.g. Maseko \& Mutasa 2018; Maseko \& Mutasa 2019). Despite the importance of language practices in delivering quality health services, there is a paucity of literature in this area, particularly on how language practices between health care professionals and their clients impacts potentially the quality of the encounter and the overall health outcomes. In particular, there is a glaring lacuna in studies that also attempt to show how language practices, in such a highly specialised field are a reflection of the hierarchical ordering of society and how these practices reproduce, and in certain instances challenge, certain language ideologies. However, some studies have attempted to show how 'language ideologies $[\ldots]$ are not only normative language orthodoxies, but are also wider forms of governmentality' (Pennycook 2013: 5) and that language uses and practices are not innocent (Ncube \& Siziba 2107) but are imbued with ideologies that commodify, ameliorate, and legitimate certain languages, particular behaviours and ways of being (Pennycook 2013).

In the west, and particularly the Americas, there has been an increasing interest in investigating language policy and practices in the health domain especially on how the discordance between the doctors and nurses' $\mathrm{L} 1$ and that of their patients creates language barriers that impact the overall health outcomes (Yeo 2004). Such studies have been conducted especially in the United States of America (USA) among immigrants with Limited English Proficiency (LEP) (Gregg \& Saha 2007). However, these studies have not gone to show how doctors' and nurses' practices are enmeshed with relations and 
practice of power and dominance, possibly because they have been conducted in an English dominant migration context. English is an unassailable global language, whose power and influence is no longer a subject of contest, particularly in officially monolingual countries such as the U.S.A. For example, Fernandez et al. (2010) investigated the health outcomes among LEP Latino diabetic population to see whether health outcomes differed from instances where the doctor was Spanish language concordant. They concluded that Latinos with language discordant doctors suffered poor health outcomes as a result of inefficient glycemic control. Although located within the broader area of language policy and practice in health, their study showed neither how such language practices are linked to ideologies of power and dominance, nor how they reproduce and mirror broader language politics beyond the health domain. Investigations of language choices and practices in health have seldom been considered within such discourses.

Lin (2000) demonstrated how certain language varieties in education, when presented as natural and the normal order of things, have the potential to subject speakers of alternative varieties to symbolic domination. By focusing on the portrayal of the mixed code as 'an ugly, insidious, monstrous animal, wildly trampling on and destroying everything...' (Lin 2000:182) in HongKong's education system, she revealed the dangers of such discourses, especially when articulated as official positions. She showed how such attitudes potentially exclude and marginalise speakers of the mixed code, due to their Limited English Proficiency. Although couched within the education discourse, Lin's findings have important implications for the present study. She demonstrates how explicitly held language ideologies such as the demonisation of the mixed code in schools precipitates into language exclusionary and marginalising practices. Similarly, in the health service provision, doctors' and nurses' language practices may effectively legitimate certain languages and varieties as the norm, a practice that does not only perpetuate symbolic domination but has implications for health outcomes. Similarly, Tamim (2014) also sought to show how language education policies resulted in symbolic violence for the excluded learners in multilingual Pakistani context. Although also situated within the education domain, Tamim, much like Lin (2000), explored how the education system in Pakistan 'perpetuate ideologies and language-based practices that result in inequality and lead to discursive constructions of the self that force the dominant into complicity with their own dominance' (Tamim 2014:112). These practices consequently impacted the 
transformative learning outcomes for the excluded groups.

Within the context of Zimbabwe, the question of language practices in health service delivery has not been addressed. Studies on language policy and practice have focused more on education and other domains to understand, for example, how 'official discourses play[s] an important role in naturalising and normalising a certain language ideology...' (Lin 2000:181). Ndhlovu (2009) has shown how language practices in education, the media, and other spaces in Zimbabwe legitimate and present Shona language as the de-facto 'national' language, owing to its numerical and political superiority, which in turn accords it symbolic power and hegemonic dominance over all other indigenous languages of Zimbabwe. He observes that while English is the all-powerful language, a status inherited from the colonial period, most indigenous languages, which are better understood by the majority of the population are marginally used in official domains, save for Shona and certain instances, Ndebele. The emergence of the Shona dominated Zimbabwe African National Union Patriotic Front (ZANU-PF) ruling elite in post-independence Zimbabwe has worked to Shona advantage, consequently presenting it as the 'unmarked' symbol of being Zimbabwean (Ncube \& Siziba 2017). Shona is used in domains and occasions where ordinarily English, the country's lingua franca, would have been considered appropriate. Streets and landmark buildings of historical significance have been given Shona names. This practice also extends to the naming of household products that are used every day by Zimbabweans (Ndhlovu 2008a). The dominance of Shona in post-colonial Zimbabwe is aptly summed thus:

In a typical counter hegemonic fashion, Shona appears to have responded to the colonially inherited English preponderance by suppressing all other African languages in the country. The Ndebele language in particular is at the mercy of the postcolonial Shonalisation wave that has seen the Shona language approximating the role of the medium of expression for the entire Zimbabwean society (Ndhlovu 2008a:306).

The exclusion of formerly minority languages, most of which are spoken in South Western Zimbabwe from use in the same domains perpetuates their marginalisation. For example, Nkomo and Maseko (2017) examined how the unofficial proscription of former minority languages for the preference of 
Shona in parliament and other government offices perpetuates Shona hegemony, thereby rendering the supposed linguistic democracy and parity of languages presumed in the linguistic provisions in the constitution a fallacy (Nkomo \& Maseko 2017). For example, they showed how non Shona speaking politicians and other people of high social standing have found themselves at the 'wrong end' of the law for using their L1 in official domains, while the use of Shona in the same domains did not invite similar sanctions and rebuke. Nkomo and Maseko (2017) cite the case of Obert Mpofu, a politician from Matabeleland and Member of Parliament who was rebuked and called to order for using Ndebele to answer a question that was posed to him in Shona by a fellow lawmaker as one vivid demonstration of the exercise of symbolic domination. Several other examples abound. Current and former political leaders have on many occasions used Shona language during their national addresses, most of which have been televised, radio broadcast, and live streamed on various social media platforms, albeit without the services of interpreters. This amounts to denial of space for other languages and has the effect of affirming that 'all Zimbabweans are expected to be proficient in Shona language to be able to identify with the Shona language and culture' (Ncube \& Siziba 2017:826).

Language practices and ideologies in the broadcasting services also reveal how languages such as English, Shona and Ndebele remain dominant in varying extents. This is despite the government's deliberate thrust to afford all languages space thrive, in line with the multilingual broadcasting policies of the Zimbabwe Broadcasting Corporation (ZBC) which seeks to promote the ideology of nationalism (Mpofu 2013). From among the indigenous languages, actual practices have been shown to favour Shona language, which enjoys more airplay and programming on radio and television. Although Ndebele does not parallel Shona in terms of time allocation quality and quantity of programmes in the state controlled ZBC, it fares better when compared to the minority languages (Maseko \& Ndlovu 2013; Nkomo \& Maseko 2017) as it does in many other domains and spaces. The amount of time allocated for respective indigenous languages in the broadcasting services is a reproduction of the social order which ameliorates speakers of Shona and legitimatise 'the unwritten yet palpable laws that privilege the Shona language and products' (Ncube \& Siziba 2017:830).

Language practices that legitimatise Shona language and subdue alternative linguistic varieties and practices are pervasive in Zimbabwe. They 
transcend the educational, broadcasting, and legal domains. Ncube and Siziba (2017) demonstrated how the field of the performing arts in Zimbabwe is not immune to such practices. They analysed how selected Ndebele speaking musicians are 'compelled to perform in the 'oppressor's language' in a Shona dominated Zimbabwean linguistic market. They showed how the presentation of Shona as the marker par excellence of Zimbabweans has not only resulted in Ndebele artists' repackaging of 'selves' and their lyrics to capture that reality, but has in certain instances compelled some artists to relocate to Harare, the epicentre of the Shona speaking peoples in Zimbabwe so as to remain relevant and maintain profitability (Ncube \& Siziba 2017). The 'reduction of Zimbabwe to Harare' (Ncube \& Siziba 2017: 831) not only poses problems for performing artists' audibility and voice but also has implications for distinctiveness, since their success comes at the expense of 'renunciation of their past, their identity, and even their language' (Tamim 2014:117).

\section{Methodology}

This study adopted a qualitative approach to investigate language experiences of selected individuals who had previously sought medical assistance from the three main hospitals in Hwange, namely Hwange colliery hospital, St. Patrick's hospital, and St Mary's hospital within the period covering July 2018 to June 2019. The three hospitals were purposively selected because they are the largest referral hospitals in Hwange district which provide healthcare services a wider population. The second author, who is a resident of Hwange used her networks to draw up a purposive sample of potential participants. Participants comprised Nambya, Tonga, Chewa, Dombe and Ndebele first language (L1) speakers. Semi-structured interviews were deployed as data collecting tools to understand how patients' language experiences as mediated by doctors' and nurses' language practices and choices in the doctor/nurse-patient linguistic exchanges were thought to be infused with the ideologies of dominant language, and how this impacted patients' overall experiences. To that end, interview questions were formulated and framed around issues relating to doctor/nurse language choices during the consultative clinical encounters, particularly where the patient and the health worker did not share a common L1. An interview guide (Appendix 1) was generated to guide the interview process. In the interview guide, questions were originally in English. Participants had an option to choose which language to use during the 
interview. All participants opted to use their L1s. The second author, a multilingual who speaks most of the languages spoken in Hwange, in addition to English, would then translate the questions into each participant's L1. With the participants' consent, interviews were audio taped and later transcribed and translated into English by the second author. A total of 15 respondents ( 9 female, 6 male), with ages ranging from 35 to 60 years participated in the study.

\section{Findings and Discussion}

\subsection{From Colonisation to 'Shonalisation': Multilingual Encounters and Language Practices in Clinical Linguistic Exchanges}

In all multilingual encounters, where participants have different linguistic backgrounds, those who wield authority and power in the domain are able to impose their language beliefs and practices on the less powerful so as to modify and influence their behaviour in the linguistic exchange (Spolsky 2004; 2009). In this study, we submit to the view that doctors and nurses are the powerful actors in clinical linguistic exchanges with patients, because they are the experts in the encounter. As such, their language choices when addressing patients are likely to influence patients' own language practices during the encounter. In the absence of a comprehensive language policy in health service delivery in Zimbabwe, we also argue here that doctors' and nurses' language practices constitute an implicit policy to manage linguistic diversity in multilingual hospitals. Hwange is a linguistically diverse district in Matabeleland North Province of Zimbabwe. Predictably, participants in this study reflected this diversity. Participants spoke Nambya, Tonga, Chewa, Dombe and Ndebele as their (L1). A negligible number also spoke and understood Shona and English as second languages (L2), albeit with varying degrees of proficiency. Participants' responses showed that this diversity poses problems for language policy in hospitals, especially in the very common encounters where patients spoke a different L1 from the doctors and nurses. In some cases, participants recalled how much of their experiences were punctuated by doctors' and nurses' use of Shona during the consultations. Ndebele and Tonga were also among languages used by nurses in a negligible number of cases. In language discordant encounters, most participants revealed how they had to submit to the language choices of the healthcare specialist. For 
example, one L1 Nambya participant recollected how she had to capitulate to the doctor's use of Shona:

I visited one of the hospitals twice this year. On both occasions I was attended to by a doctor who addressed me in Shona. I responded in Nambya but he kept going on in Shona. I had no choice but to shift to Shona. I can speak and understand a bit of Shona because it bears some similarities to Nambya. I cannot say I totally understand it so some things I could not understand. There was nothing I could do because I needed help. I was very sick

Another L1 Tonga participant recounted how he faced a similar situation:

The nurse addressed me in Shona. I do understand Shona but in matters of life and death, I usually prefer using Tonga. I do not want to be misunderstood. It's a pity that very few nurses and doctors speak Tonga around here, so sometimes we have no choice but to speak Shona even if we don't really understand it well.

In both excerpts above, the mismatch between the healthcare workers' L1 and that of the patients evidently posed a language barrier that could potentially result in ineffective communication between the parties. Although it is always taken for granted that multilinguals can use any of the many languages in their linguistic repertoire, the speaker's L1 is by far the most effective means of communication since it is understood better. Fernandez et al. (2010:170) have also shown how language barriers between English speaking physicians and Limited English Proficiency (LEP) Latinos in America contribute to poor health outcomes, a consequence hardly evident where the healthcare service was 'provided by language-concordant physicians'; because language is not just a means of communication, but also a repository of a people's culture and belief systems. Addressing patients and insisting on the use of a language that is not their L1 amounts to cultural and symbolic violence (Bourdieu 1991) because it restricts and diminishes the patients' understanding of the clinical encounter resultantly impacting health outcomes (Gregg \& Saha 2007).

In Zimbabwe, the practice of imposing the majority Shona language as the 'unmarked' symbol of Zimbabweans has been shown to be pervasive, and not only limited to health delivery. While this seems a linguistic issue, the 
implications go beyond the miscarriage of communication to being seen, particularly by speakers of minoritised languages in Hwange, as a reproduction in healthcare, of the many forms of language based marginalisation that manifest on so many other levels of Zimbabwean society (Ndhlovu 2009; Ncube \& Siziba 2017). To this end, one participant retorted:

I was really offended when the doctor could not understand my Tonga language. I find it very wrong for government to send us doctors who cannot understand our languages. These doctors don't even try to speak our language. This practice is suspicious. These people want to dominate us in all spheres and sending us doctors who can't speak our language is the final straw. Can't the government at least deploy some doctors or nurses who can speak local languages?

In the above excerpt, the participant lamented the 'suspicious' government's deployment policy and views it as a deliberate and calculated drive to further marginalise the region. Although this study elicited language related experiences, responses showed how language practices were viewed by participants within the bigger lenses of marginalisation, a narrative that has been extensively rehashed by Ndhlovu (2008a; 2008b; 2009) and in many of his other works. Critically, the pervasive ideology that legitimate the use of major endoglossic languages such as Shona and Ndebele in diverse spaces in Zimbabwe at the expense of local community languages feeds into, and is fed by, the ideology of domination. As noted by one participant, local community languages are not accorded enough recognition and use official domains, including health services provision:

Each time I went to seek medical assistance, doctors and nurses addressed me in Shona. Here in Hwange we speak different languages. The most common languages like Nambya, Tonga and Chewa are not used. You find that even our hospitals are manned by people who mainly speak Shona. Is it because they are more educated than us? Or is it a deliberate move by government to deploy speakers of Shona here?

Predictably, most non Shona L1 participants felt that the 'imposition' of Shona speaking doctors and nurses was an affront to their linguistic and cultural 
preferences and independence. As was noted earlier in this paper, language choices and practices are never innocent but are linked to ideologies of power and dominance. Although the Zimbabwean constitution recognises 16 languages as equal, language practices in health, as is the case in other domains, demonstrate that Shona language, possesses more symbolic capital compared to the rest of the indigenous languages. The plight of the dominated speakers of minoritised languages is not natural, but results from the fact that their linguistic capitals are valued poorly (Tamim 2014). By associating the diminished value of their languages to their lack of education, speakers of minoritised languages in Hwange risk legitimating this dominance, by 'limiting perceptions of possibilities for the self and misrecognising structural inequalities as deficits of self, and eventually affecting resignation to the given order' (Tamim 2014: 116).

\subsection{Shona Dominated Practices in Clinical Encounters: A Reproduction of the Zimbabwean Social and Political Order?}

Participants' language experiences demonstrated that Shona language dominates in most clinical encounters as the doctors' and nurses' preferred language, regardless of the patients' language backgrounds. Although some participants reported occasional experiences of Ndebele usage, Shona usage was experienced more than Ndebele. Explanations for such a practice, in a community inhabited predominantly by speakers of formerly minority languages cannot be understood fully outside the prisms of the social and political dynamics in which these languages coexist. Shona speakers are able to practise symbolic dominance over speakers of other indigenous languages because their language is endowed with symbolic capital (Bourdieu 1991) it derives from its association with the Zimbabwean Shona elite. Since the attainment of independence in Zimbabwe in 1980, the predominantly Shona speaking ruling ZANU PF elite has embarked conspicuously on Shona popularisation projects which promote and foreground Shona linguistic and cultural symbols as the default markers of nationhood (Ncube and Siziba, 2017; Ndhlovu, 2008b; 2009). It is therefore not surprising that such a scenario reproduces itself in clinical encounters in health delivery service. Matabeleland North, the cradle of the majority of minoritised languages is also the bane of underdevelopment in Zimbabwe. In the Zimbabwean body politic, speakers of 
minoritised languages do not have a meaningful representation in the power matrix. This translates to negligible influence in the articulation and direction of the development agenda for Matabeleland in general. Resultantly, the provinces of Matabeleland lag behind in development compared to the rest of the country and Mashonaland in particular. Consequently, schools have recorded the lowest ' $O$ ' Level pass rates in the country, with some schools recording zero percent pass rates, meaning that the province can hardly be a catchment area for trainee doctors and nurses in the country. Most students who make it to the medical and nursing schools are mostly drawn from wellresourced schools in Mashonaland. It therefore goes without saying that upon completion of training, the same end up being deployed to take up vacancies even beyond their home areas, taking along with them, their own languages. According to Ncube and Siziba (2017), the conflation of Zimbabwe with Harare and the centralisation of all government activities there tilts the advantage to Mashonaland provinces, owing to their proximity to Harare. Citizens resident in the excluded Matabeleland Provinces end up 'attribut[ing] their failure to their own lack of natural ability, without realising that the entire rules of the game were structured to conspire in their defeat' (Tamim 2014 :117). We therefore submit that doctors' and nurses' reported language practices in clinical encounters are a reproduction of the enduring Shona hegemony and dominance which is, to a considerable extent, mediated and legitimated, in some instances by various state sanctioned popularisation projects (see also Ndhlovu 2008a; 2009). This dominance also presents itself 'through the use of Shona in national public forums, and the insistence that non Shona people speak or accede to the saturation of this language in the Zimbabwean space...' (Ncube \& Siziba 2017:826). Doctors' and nurses' reported language choices and practices in clinical encounters, if considered within 'the hierarchy of a wider language policy, can have implications for inequality and poverty' (Tamim 2014:111) particularly for the excluded minoritised groups.

\subsection{Language Concordant Health Practitioners and Interpreter Services: A Panacea to the Language Barrier?}

Findings of the study have thus far shown how the mismatch between the health practitioners' $\mathrm{L} 1$ and that of the patients did not only diminish the 
quality of the clinical experience but also fed into the growing voices on the marginalisation of the previously minoritised indigenous languages in the health sector. Because the language barrier in health has potentially fatal outcomes, there is need, at best, for the deployment of language concordant health practitioners, or at worst, the assignation of interpreters. Although the doctor-patient confidentiality protocols are likely to impinge on the mechanics of the interpreting practice in clinical encounters, some participants strongly suggested that such a service would add invaluable contribution in breaking down the language barrier. For example, one Dombe speaking participant thought that it was better to compromise the doctor patient confidentiality if that was the only shot she had at saving their own lives:

If it is true that there are no doctors who speak Dombe, at least we should have interpreters to help us understand what the doctors and nurses will be saying in their language. It is better that the secrets about my health be known by the next person if that will help in making me understand the doctors' instructions. But government must send doctors who speak local languages to solve this problem permanently.

A number of participants shared similar views. Yeo (2004) has also proposed the provision of interpreter services as an indispensable language barrier breaking panacea in health care. The maintenance of doctor-patient confidentiality however places a demand on healthcare institutions for the use of innovative approaches to the practice of interpreting. For example, as an alternative to the traditional use of onsite professional interpreters, Brach and Fraser (2000) proposed the deployment of remote electronic interpretations, the use of ad-hoc interpreters in the form of hospital staff taken off other duties and the use of family members or even strangers. However, some studies have shown how the use of such ad-hoc interpreters may diminish the quality of the interpretation potentially, especially if the interpreter does not fully comprehend the content of the medical advice (Yeo 2004). However, what is clear from the findings is that the predominant practice of doctors' and nurses' of using Shona as an uncontested alternative to English in doctor-patient clinical encounters should be dismantled, to afford speakers of formerly minoritised languages inclusive linguistic experiences in healthcare. 


\section{Conclusion}

In this article, we have shown how doctors' and nurses' language choices in clinical encounters with patients are not at all innocent but rather, are imbued and infused with ideologies of domination. This paper focused on language experiences of patients in Hwange district, an area inhabited by speakers of formerly minoritised indigenous languages of Zimbabwe. We have attempted to show how the predominant practice by doctors and nurses to use Shona language in clinical encounters with non-Shona patients is a reproduction in the health system, of the Shona dominance visible in all levels of society in post-colonial Zimbabwe. Findings of the study further feed into the narrative that, in the absence of a comprehensive language policy in Zimbabwe, and language policy in health service delivery, doctors' and nurses' language practices constitute an implicit policy, which policy tends to mirror broader language ideologies at the state level. These ideologies in post-colonial Zimbabwe have tended to present Shona language as the natural alternative to the colonially imposed English language. This practice has occasioned the valorisation of Shona in postcolonial Zimbabwe, ultimately presenting it and its use in official domains as the 'new order of things'. The study proposed the deployment of language concordant health practitioners and the use of interpreter services to ease the language barrier and possibly foster inclusive language practices in health delivery, particularly for speakers of former minority languages. This study was, however, limited to analysing language experiences of selected participants who had a history of medical assistance in three main hospitals in Hwange. Future studies could also investigate doctors' and nurses' own experiences to understand how their language practices are infused with their own language ideologies.

\section{References}

Bamgbose, A. 2003. A Recurring Decimal: English in Language Policy and Planning. World Englishes 22, 4: 419 - 431. Available at: https://www.blackwellpublishing.com/content/bpl_images/Journal_Sam ples/WENG0883-2919 22 4/310.PDF (Accessed 20 January 2019.)

Bamgbose A. 1991. Language and the Nation: The Language Question in subSaharan Africa. Edinburgh: Edinburgh University Press for International African Institute. 
Bourdieu, P. 1991. Language and Symbolic Power. Cambridge: Polity Press. Brach, C. \& I. Fraser 2000. Can Cultural Competency Reduce Racial and Ethnic Health Disparities? A Review and Conceptual Model. Medical Care Research and Review 57, 1:181 - 217. Available at:

https://www.researchgate.net/publication/12236017 Can Cultural Com petency_Reduce_Racial_And_Ethnic_Health_Disparities_A_Review_A nd_Conceptual_Model (Accessed on 4 July 2020.)

Chimhundu, H. 1992. Early Missionaries and the Ethnolinguistic Factors during the 'Invention of Tribalism' in Zimbabwe. Journal of African History 44: 87 - 109.

Christie, P. \& C. McKinney 2017. Decoloniality and 'Model C' Schools: Ethos, Language and the Protests of 2016. Education as Change 21, 3:121.

Chronicle, October 9 2019. Available at:

https://www.chronicle.co.zw/nurses-recruitment-sparks-uproar/.

Fernandez, A., D. Schillinger, E.M. Warton, N. Adler, H.H Moffet, Y. Schenker, V. Salgado, A. Ahmed \& A.J. Karter 2010. Language Barriers, Physician - Patient Language Concordance, and Glycemic Control among Insured Latinos with Diabetes: The Diabetes Study of Northern California. Journal of General Internal Medicine 26, 2 :170 - 176. Available at: https://pubmed.ncbi.nlm.nih.gov/20878497/ (Accessed on 17 October 2019.)

Government of Zimbabwe, 2013. Constitution of Zimbabwe, Amendment (No. 20). Available at:

http://www.parlzim.gov.zw/component/k2/download/1290_da9279a815 57040d. (Accessed on 09 February 2019.)

Gregg, J. \& S. Saha 2007. Communicative Competence: A Framework for Understanding Language Barriers in Healthcare. Journal of General Internal Medicine 22, 2: 368 - 370. Available at:

https://link.springer.com/article/10.1007/s11606-007-0364-4. (Accessed on 16 June 2019.)

Kadenge, M. \& D. Nkomo 2011. The Politics of the English Language in Zimbabwe. Language Matters 42, 2: 248 - 263. Available at: https://www.tandfonline.com/doi/abs/10.1080/10228195.2011.581679. (Accessed on 20 July 2019.)

Lin, A.M.Y. 2000. Bilingualism or Linguistic Segregation? Symbolic Domination, Resistance and Codeswitching in Hong Kong Schools. In Li, 
D.S.C., A.M.Y. Lin \& W.K. Tsang (eds.): Language and Education in Postcolonial Hong Kong. Hong Kong: Hong Kong Linguistic Society. Available at:

https://www.academia.edu/3042191/Bilingualism_or_linguistic_segregat ion 1 Symbolic domination resistance and code switching in Hong

Kong_schools. (Accessed on 23 September 2019.)

Loos, E. 2000. Language Choice, Linguistic Capital and Symbolic Domination in the European Union. Language Problems and Language Planning 24, 1: 37 - 53. Available at: https://benjamins.com/catalog/lplp.24.1.04loo. (Accessed on 15 March 2019.)

Maseko, B. \& D.E. Mutasa 2018. The Influence of Kalanga Parental Language Ideologies on Children's Language Practices. Language Matters 49, 3: 47-66. Available at:

https://www.tandfonline.com/doi/abs/10.1080/10228195.2018.1496132. (Accessed on 6 December 2018.)

Maseko, B. \& D. Mutasa 2019. 'Only Tonga Spoken Here!': Family Language Management among the Tonga in Zimbabwe. Southern African Linguistics and Applied Language Studies 37, 4: 289 - 302. Available at: https://www.tandfonline.com/doi/abs/10.2989/16073614.2019.1692676. (Accessed on 13 December 2019.)

Maseko, B. \& K. Ndlovu 2013. Indigenous Languages and Linguistic Rights in the Zimbabwean Media. Online International Journal of Arts and Humanities 2, 5:150 - 156. Available at:

http://onlineresearchjournals.org/IJAH/cont/2013/jun.htm. (Accessed on 8 November 2019.)

Mpofu, P. 2013. Multilingualism, Localism and the Nation: Identity Politics in the Zimbabwe Broadcasting Corporation. Awarded at, University of South Africa. Available at: http://uir.unisa.ac.za/handle/10500/18663.

Msindo, E. 2005. Language and Ethnicity in Matabeleland: Ndebele-Kalanga Relations in Southern Zimbabwe, 1930 - 1960. The International Journal of African Historical Studies 38, 1: 79 - 103. Available at: https://www.jstor.org/stable/40036464?seq=1\#metadata info tab conte nts. (Accessed on 11 March 2019.)

Ncube, G. \& G. Siziba 2017. Compelled to Perform in the 'Oppressor's' Language? Ndebele Performing Artists and Zimbabwe's Shona-centric Habitus. Journal of Southern African Studies.43, 4: 825 - 836. Available at: 
https://www.tandfonline.com/doi/full/10.1080/03057070.2017.1313609. (Accessed on 19 February 2019.)

Ndlovu, E. 2013. Mother Tongue Education in Official Minority Languages of Zimbabwe: A Language Management Critique. Awarded at, University of the Free State, Bloemfontein. Available at: http://scholar.ufs.ac.za:8080. Ndhlovu, F. 2008a. Gramsci, Doke and the Marginalisation of the Ndebele Language in Zimbabwe. Journal of Multilingual and Multicultural Development 27, 4: 305 - 318. Available at:

https://www.tandfonline.com/doi/abs/10.2167/jmmd445.1 (Accessed on 12 June 2019.)

Ndhlovu, F. 2008b. The Conundrums of Language Policy and Politics in South Africa and Zimbabwe. Australian Journal of Linguistics 28, 1: 59 - 80. Available at:

https://www.tandfonline.com/doi/full/10.1080/07268600701877499.

(Accessed on 11 August 2019.)

Ndhlovu, F. 2009.The Politics of Language and Nation Building in Zimbabwe. Bern: Peter Lang Publishers.

Ndlovu-Gatsheni, S.J. 2008. The Ndebele Nation: Reflections on Hegemony, Memory and Historiography. Amsterdam - Pretoria, Rozenberg: UNISA Press.

Ndlovu-Gatsheni, S. J. 2015. Decoloniality in Africa: A Continuing Search for a New World Order. Australasian Review of African Studies 36, 2: 22 50. Available at: https://afsaap.org.au/assets/sabelo_ndlovugatsheni_pp22-50.pdf (Accessed on 13 December 2019.)

Nkomo, D. \& B. Maseko 2017. Sixteen Officially Recognised Languages: Milestones and Challenges for Linguistic Democracy in Zimbabwe. In Ralarala, M.K., K. Barris, E. Ivala, \& S. Siyepu (eds.): African Languages and Language Practice Research in the $21^{\text {st }}$ Century: Interdisciplinary Themes and Perspectives. Cape Town: CASAS.

Pennycook, A. 2013. Language Policies, Language Ideologies and Local Language Practices. In Wee, L., R.B.H. Goh \& L. Lim. (eds.): The Politics of English: South Asia, Southeast Asia and the Asia Pacific. Amsterdam: John Benjamins Publishing Company.

Ren, L. \& G. Hu 2013. Prolepsis, Syncretism, and Synergy in Early Language and Literacy Practices: A Case Study of Family Language Policy in Singapore. Language Policy 12: 63 - 82. Available at: https://link.springer.com/article/10.1007/s10993-012-9260-9 
(Accessed on 19 August 2019.)

Spolsky, B. 2004. Language Policy. Cambridge: Cambridge University Press. Spolsky, B. 2009. Language Management. Cambridge: Cambridge University Press.

Tamim, T. 2014. Language in Education and Symbolic Violence in Pakistan. In Solly, M. \& E. Esch (eds.): Language Education and the Challenges of Globalisation: Sociolinguistic Issues. Newcastle: Cambridge Scholars Publishing.

Woolard, K.A. \& B.B. Schieffelin 1994. Language Ideology. Annual Review of Anthropology 23: 55 - 82. Available at:

https://www.annualreviews.org/doi/abs/10.1146/annurev.an.23.100194.0 00415. (Accessed on 17 September 2019.)

Yeo, S. 2004. Language Barriers and Access to Care. Annual Review of Nursing Research 22: 59 - 73. Available at:

https://www.researchgate.net/publication/8345471_Language_Barriers _ and Access to Care (Accessed on 23 June 2019.)

\author{
Busani Maseko \\ Post-Doctoral Research Fellow \\ African Language Studies \\ Rhodes University \\ Grahamstown \\ b.maseko@ru.ac.za
}

Prisca Matunge Honours Student Department of Languages Lupane State University Lupane Zimbabwe Matungeprisca28@gmail.com 